\title{
Dietary glycaemic index and glycaemic load among Australian children and adolescents: results from the 2011-2012 Australian Health Survey
}

\author{
Molly Jones ${ }^{1}$, Alan W. Barclay ${ }^{2}$, Jennie C. Brand-Miller ${ }^{1,2,3}$ and Jimmy Chun Yu Louie ${ }^{1,3,4 *}$ \\ ${ }^{1}$ School of Life and Environmental Sciences, Faculty of Science, The University of Sydney, Sydney, NSW 2006, Australia \\ ${ }^{2}$ Glycemic Index Foundation, St Leonards, NSW 2065, Australia \\ ${ }^{3}$ Charles Perkins Centre, The University of Sydney, Sydney, NSW 2006, Australia \\ ${ }^{4}$ School of Biological Sciences, Faculty of Science, The University of Hong Kong, Pokfulam, Hong Kong, People's Republic of China \\ (Submitted 11 October 2015 - Final revision received 7 March 2016 - Accepted 6 April 2016 - First published online 12 May 2016)
}

\section{Abstract}

This study aimed to examine the dietary glycaemic index (GI) and glycaemic load (GL) of Australian children and adolescents, as well as the major food groups contributing to GL, in the recent 2011-2012 Australian Health Survey. Plausible food intake data from 1876 children and adolescents (51\% boys), collected using a multiple-pass 24-h recall, were analysed. The GI of foods was assigned based on a step-wise published method using values from common GI databases. Descriptive statistics were calculated for dietary GI, GL and contribution to GL by food groups, stratified by age group and sex. Linear regression was used to test for trends across age groups for BMI, dietary GI and GL, and intakes of energy, nutrients and food groups. Pearson's $\chi^{2}$ test was used to test for differences between age groups for categorical subject characteristic variables. Mean dietary GI and GL of participants were 55.5 (SD 5.3) and 137.4 (SD 50.8), respectively. The main contributors to dietary GL were starchy foods: breads, cereal-based dishes, breakfast cereals, flours, grains and potatoes accounted for $41 \%$ of total GL. Sweetened beverages, fruit and vegetable juices/drinks, cake-type desserts and sweet biscuits contributed $15 \%$. No significant difference (at $P<0.001$ ) was observed between sexes. In conclusion, Australian children and adolescents appear to consume diets with a lower GI than European children. Exchanging high-GI foods for low-GI alternatives within core and non-core foods may improve diet quality of Australian children and adolescents.

\section{Key words: Glycaemic index: Glycaemic load: National Nutrition Survey: Australian youths: Children: Adolescents}

There is mixed evidence suggesting that diets low in glycaemic index (GI) and/or glycaemic load (GL) are associated with better health by improving access to stored metabolic fuels, decreasing hunger and promoting weight loss ${ }^{(1-3)}$, as well as decreased risk of chronic diseases such as type 2 diabetes mellitus and $\mathrm{CVD}^{(4,5)}$. A healthy low-GI/GL diet would ideally contain abundant quantities of vegetables, fruits and legumes, moderate amounts of protein and healthy fats, and be low in refined grain products and added sugars ${ }^{(6)}$. A low-GI/GL diet therefore closely resembles the recommendations in national dietary guidelines ${ }^{(7-10)}$.

High-GI/GL diets, on the other hand, are thought to predict postprandial hyperinsulinaemia, encouraging the development of insulin resistance ${ }^{(11)}$. Hence, it has been hypothesised that, among other factors, high-GI foods are contributing to the obesity epidemic ${ }^{(12)}$. Increased prevalence of type 2 diabetes mellitus $^{(13)}$, gestational diabetes mellitus ${ }^{(14,15)}$, as well as colorectal and endometrial cancers, ${ }^{(16)}$ has also been linked to high-GI/GL diets. Many studies have examined the relationship between dietary GI/GL and health outcomes in children and adolescents. For example, Barba et al. ${ }^{(17)}$ showed in a study of
3734 Italian children aged 6-11 years that dietary GI is an independent predictor of body fat distribution and total adiposity. In contrast, Murakami et al. ${ }^{(18)}$ reported that dietary GL but not GI was positively associated with an increased risk of overweight in Japanese boys and girls, and male adolescents. A German study ${ }^{(19)}$ also reported that habitual high dietary GI during puberty is prospectively associated with increased type 2 diabetes mellitus risk markers such as homeostatic model assessment (HOMA)-insulin resistance.

As GL is a function of both carbohydrate quality - that is GI - and quantity - that is amount of carbohydrate consumed age and sex variations in GL are expected, as boys generally have higher energy, hence carbohydrate, intake than girls; the same is also true for younger $v$. older children. Our previous analysis based on the 2007 Australian National Children's Nutrition and Physical Activity Survey (2007 ANCNPAS) $)^{(20)}$ supports this notion where variations in GL contribution by different food groups were seen between sexes and age groups.

Despite the potential to contribute to poor health outcomes, there is a lack of nationally representative data on dietary GI

Abbreviations: AHS, Australian Health Survey; GI, glycaemic index; GL, glycaemic load; PAL, physical activity level.

* Corresponding author: Dr J. C. Y. Louie, fax +85225599114, email jimmyl@hku.hk 
and GL. In Australia, the last reported analysis of children's intake was an analysis by our group based on a survey in $2007-2008^{(20)}$. As food product formulations are constantly changing in reaction to consumer demand, and low-GI products have become more common compared with a decade ago ${ }^{(21,22)}$, it is possible that the results of the previous survey may no longer represent the current situation. Since then, the 2011-2012 Australian Health Survey (AHS) ${ }^{(23)}$ generated data sets for food intake in children and adolescents. Our aim therefore was to describe current dietary GI and GL and explore the main food sources contributing to the dietary GL of Australian youths according to age and sex.

\section{Methods}

Data source

Data from the National Nutrition and Physical Activity Survey (NNPAS) component of the 2011-2012 AHS were used. The AHS was conducted by the Australian Bureau of Statistics ${ }^{(23)}$ between 2011 and 2012. The methodology of the NNPAS has previously been described in detail ${ }^{(24)}$. Briefly, the sample population was selected using a stratified multistage area sample of private dwellings, with a response rate of $77 \%$ for the NNPAS component ${ }^{(24)}$. Trained interviewers conducted face-to-face interviews with a selected adult member of the respondent household $^{(24)}$. The survey collected information on the dietary intakes of food and beverages, as well as the use of supplements, using the computer-assisted, multiple-pass 24-h recall method.

\section{Anthropometric measurements}

Weight and height were measured without shoes and heavy clothing where possible, using a digital scale (to the nearest $0 \cdot 1 \mathrm{~kg}$ ) and a stadiometer (to the nearest $0 \cdot 1 \mathrm{~cm}$ ), respectively ${ }^{(24)}$. BMI was calculated as weight in kilograms divided by the square of height in metres. Participants were then classified into underweight, normal weight, overweight or obese based on the international age- (in half yearly intervals) and sex-specific BMI cut-offs ${ }^{(25)}$.

\section{Dietary assessment}

All participants aged $2-18$ years ( $n$ 2651) had dietary information collected in a face-to-face interview between 29 May 2011 and 9 June 2012. A second 24-h recall was conducted in approximately $60 \%$ of these subjects via phone interview, at least $8 \mathrm{~d}$ after the face-to-face interview. Parents reported the intake of children under the age of 5 years, and children aged 6-8 years were allowed to assist their parents during the interview. Children and adolescents aged 9-14 years reported their own dietary intake with or without the help of their parents, and adolescents aged 15 years or above reported their own intake independently ${ }^{(24)}$. Dietary intake data were entered into a purpose-built database, and were translated into nutrient intake using the AUSNUT 2011-2013 database ${ }^{(26)}$. A method previously described by our group was used to assign GI values to individual food items in AUSNUT 2011-2013 ${ }^{(27,28)}$. In brief, foods with $\leq 2.5 \mathrm{~g}$ available carbohydrates/100 g were assigned a GI value of 0 (Step 1, $n$ 1752). All remaining foods had their GI values assigned based on a step-wise, systematic approach, using either the GI value of an exact match (Step 2, $n$ 363) or the closest match (Step 3, $n$ 1738) in one of the four commonly used GI databases ${ }^{(21,22,29,30)}$. Foods without a match in these tables were either assigned a weighted GI value if they are mixed dishes, which could be disassembled into individual ingredients (Step 4, $n$ 1526), or the median GI of the corresponding food subgroup (Step $5, n$ 205). A small proportion ( $n$ 60) of foods was assigned a default $\mathrm{GI}^{(22)}$, as none of the earlier steps could be used to assign a GI to them.

Foods were grouped together based on the minor food groups in AUSNUT 2011-2013 ${ }^{(31)}$ to enable identification of the main food sources contributing to dietary GL. The AUSNUT food groups were renamed and shortened for better presentation in text, tables and figures. A complete list of the original $v$. renamed food groups can be found in the online Supplementary Table S1.

\section{Calculation of dietary glycaemic index and glycaemic load}

The GL of each food was calculated by GI (\%) × available carbohydrates ( $\mathrm{g}$ ) in a serving of that specific food. The daily dietary GL of each subject was then calculated as the sum of GL from all foods consumed in that day. Dietary GI was calculated by the following formula:

$$
\frac{\text { dietary GL }}{\text { total available carbohydrate intake in the day }} \times 100 \%{ }^{(20,32)} \text {. }
$$

\section{Data cleaning}

In this study, only the first $24-\mathrm{h}$ recall collected from a faceto-face interview was used, in order to reduce the influence of under-reporting, which is common in the follow-up recall via phone interview ${ }^{(33)}$. The plausibility of the food intake data was assessed using the equation proposed by Goldberg et al. ${ }^{(34)}$ to exclude extreme low and high reporters. As the survey did not provide data on physical activity level (PAL), the standard PAL of 1.55 was used in the calculation of the cut-offs, as per the AHS recommendations ${ }^{(24)}$. The lower and upper $95 \% \mathrm{CI}$ of PAL of 1.55 (i.e. 0.87 and 2.76 ) were used as the cut-off values for extreme low and high reporters, respectively ${ }^{(34)}$. On the basis of this method, 244 extreme low reporters and 530 extreme high reporters were identified. A sensitivity analysis was performed in which results of all participants and only those with plausible data were compared, and no material differences in the direction of trends and conclusions were observed. Hence, the extreme mis-reporters were excluded in the final analysis. The final data set included 1876 individuals, of whom $51.3 \%$ were boys.

\section{Statistical analysis}

The AHS had over-sampled males to females, and a much larger percentage of adults to children. Furthermore, major city residents were over-represented ${ }^{(23)}$. Sample weighting was applied to the data set to allow generalisation of the findings to 
the general Australian population ${ }^{(24,35)}$. Data were presented as mean values and standard deviations for continuous variables, and as percentages for categorical variables. The number of consumers for each age group and sex for the top twenty food groups contributing to GL was counted (see online Supplementary Table S2). The percentage that each food group contributed to the dietary GL was calculated as $\frac{\sum \text { GL of foods in food group consumed }}{\sum \text { GL of all foods consumed }} \times 100 \%$. For the food sources analyses, per capita and per consumer results were both presented. Per capita analyses included all subjects and provide a snapshot of an average individual, whereas per consumer analyses included only the participants who had reported consumption of the specific food group on the day of the food recall. Age groups pre-defined in the AHS were used in the stratified analysis to allow better comparisons across surveys within Australia, and post hoc comparisons between age groups were performed by using the Bonferoni post hoc test for oneway ANOVA. Differences between sexes for each age group were tested by one-way ANOVA. Linear regression was used to test for trends across age groups. Statistical significance is set at $P<0.001$ to minimise type I error ${ }^{(36)}$. All statistical analyses were carried out using SPSS version 22.0 (IBM).

\section{Results}

The characteristics of the participants are summarised in Table 1. The mean BMI of the study population was $19 \cdot 0$ (sD 3.8$) \mathrm{kg} / \mathrm{m}^{2}$, with 18.1 and $5.1 \%$ considered overweight and obese, respectively. There was no significant difference between the BMI of boys and girls (19.0 (SD 3.8) v. 19.0 (sD 3.7$) \mathrm{kg} / \mathrm{m}^{2} ; \quad P=0.936$ ), although there was a nonsignificantly higher proportion of overweight and obese participants among boys than among girls (25.4 v. 20.9\%). Extreme low reporters excluded from the analysis were older (12.7 (SD 4.6 ) years) and had a higher mean BMI of 22.5 (SD 4.7$) \mathrm{kg} / \mathrm{m}^{2}$, whereas extreme high reporters excluded had a slightly lower mean age of 9.1 (SD 4.8) years and a lower BMI of 17.6 (sD $3 \cdot 2) \mathrm{kg} / \mathrm{m}^{2}$, compared with participants with plausible dietary intake (all $P<0.001$ tested by ANOVA).

Table 2 summarises the dietary intake of the subjects, stratified by age groups. Across the sample, the mean dietary GI and GL were 55.5 (SD 5.3) and 137.4 (SD 50.8), respectively. There were increasing linear trends of dietary GI and GL, energy intake and energy from fat as age increases (all $P_{\text {trend }}<0 \cdot 001$ ). Marginally significant increasing trends as age increases were also observed for dietary GL per megajoule and energy from protein (both $P_{\text {trend }}=0.002$ ). On the other hand, significant decreasing trend across age groups were observed for energy from carbohydrates and sugars, and fibre density (all $\left.P_{\text {trend }}<0 \cdot 001\right)$.

Bread and bread rolls (14.7\%), cereal-based dishes (10.5\%) and breakfast cereals (ready to eat) $(6.8 \%)$ were identified as the top three contributors to dietary GL, accounting for nearly $40 \%$ of the dietary GL on a per capita basis. The ranking of GL contributions per food group varied considerably among age groups (online Supplementary Table S3).

Table 3 summarises per capita contribution to dietary GL by the top twenty contributors, stratified by age group. As age increased, bread and bread rolls, sweet biscuits, dairy milk, all varieties of fruit (all $P_{\text {trend }}<0.001$ ) and fruit and vegetable juices and drinks $\left(P_{\text {trend }}=0.005\right)$ contributed less and less to dietary GL. In contrast, cereal-based dishes, potatoes, sweetened beverages (all $\left.P_{\text {trend }}<0.001\right)$ and pastas $\left(P_{\text {trend }}=0.001\right)$ contributed more and more as age increased. Post hoc comparisons (all $P<0.001$ ) revealed that children aged $2-3$ years had significantly higher intakes of dairy milk and tropical and subtropical fruit than participants aged 4-18 years, and lower intake of frozen milk products than 9-13-year-olds only. Children aged 4-8 years were found to have higher intake of bread and bread rolls than 9-13-year-olds; higher intake of pome fruit and lower intake of cereal-based dishes than 14-18-year-olds; and lower intake of sweetened beverages than

Table 1. Subject characteristics*

(Mean values and standard deviations (continuous variables) and percentages (categorical variables))

\begin{tabular}{|c|c|c|c|c|c|c|}
\hline & $2-3$ years & $4-8$ years & $9-13$ years & $14-18$ years & $P \dagger$ & All children \\
\hline$n$ & 213 & 552 & 630 & 481 & - & 1876 \\
\hline BMI $\left(\mathrm{kg} / \mathrm{m}^{2}\right) \ddagger$ & & & & & $<0.001$ & \\
\hline Mean & $16 \cdot 9$ & $16 \cdot 6$ & $19 \cdot 4$ & $22 \cdot 0$ & & $19 \cdot 0$ \\
\hline SD & $2 \cdot 1$ & 2.4 & 3.6 & 3.5 & & 3.8 \\
\hline Underweight (\%) & $6 \cdot 1$ & $4 \cdot 7$ & 3.7 & $8 \cdot 6$ & $<0.001$ & 5.5 \\
\hline Normal weight (\%) & $65 \cdot 7$ & 74.9 & $69 \cdot 8$ & 71.8 & & 71.3 \\
\hline Overweight (\%) & $22 \cdot 1$ & $14 \cdot 0$ & $21 . .6$ & $16 \cdot 3$ & & $18 \cdot 1$ \\
\hline Obese $(\%)$ & $6 \cdot 1$ & $6 \cdot 4$ & 4.9 & $3 \cdot 3$ & & $5 \cdot 1$ \\
\hline Male (\%) & $51 \cdot 2$ & $52 \cdot 7$ & $50 \cdot 8$ & $50 \cdot 3$ & 0.874 & $51 \cdot 3$ \\
\hline Living in urban area (\%) & $71 \cdot 0$ & $67 \cdot 6$ & 67.5 & $66 \cdot 3$ & 0.679 & $67 \cdot 6$ \\
\hline Proportion in the highest SEIFA quintile (\%) & $20 \cdot 2$ & $25 \cdot 7$ & $26 \cdot 5$ & $24 \cdot 7$ & 0.315 & $25 \cdot 1$ \\
\hline Proportion in the highest decile of household income $(\%) \S$ & 3.5 & $8 \cdot 2$ & $6 \cdot 3$ & $6 \cdot 2$ & 0.151 & 6.5 \\
\hline Born in Australia (\%) & $94 \cdot 8$ & 92.9 & 87.6 & $87 \cdot 7$ & $<0.001$ & $90 \cdot 0$ \\
\hline
\end{tabular}

SEIFA, Socio-Economic Indexes for Areas.

* Data were weighted to account for over- or under-sampling to enable representation of the general Australian children and adolescent population.

$\dagger P$ values represent $P_{\text {for trend }}$ across age groups tested by linear regression for continuous variables, and for categorical variables the $p$ values were tested by $x^{2}$ test.

$\ddagger n 213,549,630,479,1871$, respectively, due to missing data.

$\S n 199,515,584,388,1686$, respectively, due to missing data. 


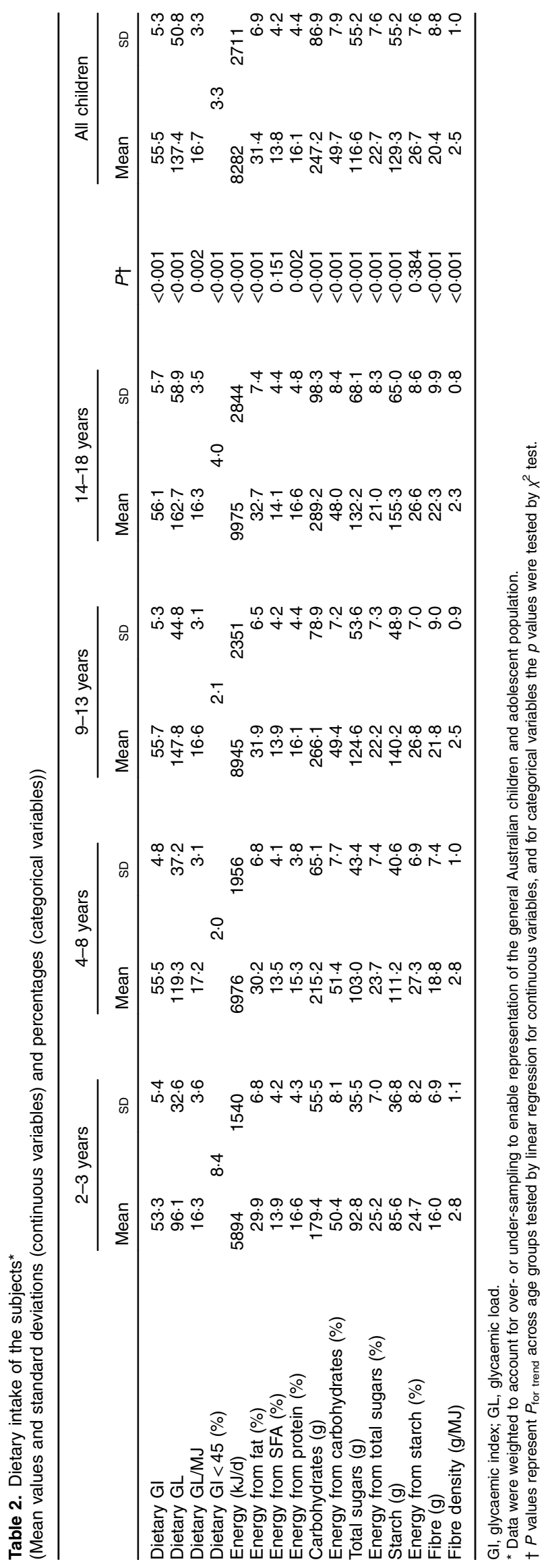

their counterparts aged 9-18 years. Participants aged 14-18 years also had higher intake of sweetened beverages and lower intake of pome fruit than 9-13-year-olds. No significant difference (at $P<0.001$ ) was observed between sexes (online Supplementary Table S4).

Per consumer analyses revealed a somewhat different picture (Table 4). Most trends increased with age, but dairy milk $\left(P_{\text {trend }}<0.001\right)$ and fruit $\left(P_{\text {trend }}<0.001\right.$ for tropical and subtropical fruit; and $P_{\text {trend }}=0.008$ for pome fruit) decreased with age. The only significant difference revealed by post hoc comparisons was that consumers aged 2-3 years had significantly higher dairy milk intake than consumers aged 4-18 years. No significant difference (at $P<0.001$ ) was observed between sexes (online Supplementary Table S5).

\section{Discussion}

In this study, we report recent trends in GI and GL of a nationally representative sample of Australian children and adolescents, revealing the main food groups contributing to GL. Overall, the mean GI of participants was 56 (SD 5) and the GL was 137 (SD 51). Starchy foods such as breads, breakfast cereals and cereal-based dishes (e.g. pizza) were the main contributors to dietary GL.

Our data suggest that Australian children and adolescents in 2011-2012 had a slight increase in GI and GL from 54 to 56 and from 133 to 137 when compared with data from the 2007 ANCNPAS $^{(20)}$. Both are considerably lower than that found in the Australian Raine study cohort (GI: 58; GL: 158) in $2003-2005^{(37)}$. Many studies ${ }^{(18,38-42)}$ have reported the dietary GI and GL in different paediatric populations around the world, which is relevant in benchmarking the Australian situation. For example, the current dietary GI and GL of Australian children and adolescents are 3 and 46 units lower than that reported in the UK National Diet and Nutrition Survey of children and adolescents aged $4-18$ years $^{(42)}$. A study of German children and adolescents aged 9-15 years reported dietary GI of 56 and GL of 134 , similar to our findings ${ }^{(19)}$. An Italian study of 3736 children aged 6-11 years reported a comparable dietary GI of 54, but a much higher dietary GL of $169^{(17)}$. Given the similarity in the dietary GI but markedly different dietary GL observed in different populations, it is reasonable to conclude that the difference in dietary GL is mainly a result of differences in total carbohydrate intake. In the present study, the mean carbohydrate intake was $247 \mathrm{~g} / \mathrm{d}$, compared with 274 and $310 \mathrm{~g} / \mathrm{d}$ reported in the Raine study cohort ${ }^{(37)}$ and ARCA project ${ }^{(17)}$, respectively. Furthermore, the similar results in the current analyses and our previous study in the 2007 ANCNPAS $^{(20)}$ suggested that the greater variety of low-GI food available in the market between 2007 and 2012 did not have a great impact on the population dietary GI and GL. Other interventions may be necessary to reduce the dietary GI and GL of Australian youths.

It should be noted that while the SD of dietary GI is considered small (approximately 10\% of the mean), the SD for GL and \%GL contribution are very large. Given the small SD of GI, which indicates moderate inter-individual variance, the large SD for GL could be a reflection of a large variance in total 
Table 3. Per capita percentage dietary glycaemic load contribution from the top twenty food groups, in subjects aged 2-18 years*

(Mean values and standard deviations)

\begin{tabular}{|c|c|c|c|c|c|c|c|c|c|c|c|}
\hline \multirow[b]{2}{*}{ Food groups } & \multicolumn{2}{|c|}{$2-3$ years } & \multicolumn{2}{|c|}{$4-8$ years } & \multicolumn{2}{|c|}{$9-13$ years } & \multicolumn{2}{|c|}{$14-18$ years } & \multirow[b]{2}{*}{$P_{\text {trend }} \dagger$} & \multicolumn{2}{|c|}{ All children } \\
\hline & Mean & SD & Mean & SD & Mean & SD & Mean & SD & & Mean & SD \\
\hline Bread and bread rolls & 14.5 & $12 \cdot 1$ & $18 \cdot 1$ & 13.5 & $14.0 \ddagger$ & $12 \cdot 4$ & $12 \cdot 0$ & $13 \cdot 3$ & $<0.001$ & 14.7 & $13 \cdot 2$ \\
\hline Cereal-based dishes & $6 \cdot 7$ & 11.5 & 7.5 & $12 \cdot 9$ & 11.4 & $15 \cdot 9$ & $14 \cdot 3 \S \ddagger$ & $17 \cdot 8$ & $<0.001$ & 10.5 & $15 \cdot 4$ \\
\hline Breakfast cereals (ready to eat) & 7.6 & $9 \cdot 4$ & 7.7 & 9.9 & $6 \cdot 0$ & 8.9 & $6 \cdot 3$ & $11 \cdot 1$ & 0.021 & $6 \cdot 8$ & 9.9 \\
\hline Flours, cereals and starches & $5 \cdot 7$ & $13 \cdot 1$ & 3.9 & $10 \cdot 8$ & 4.0 & 11.6 & $5 \cdot 7$ & $14 \cdot 0$ & 0.493 & 4.6 & $12 \cdot 2$ \\
\hline Potatoes & $2 \cdot 8$ & $5 \cdot 8$ & 3.6 & 7.6 & $5 \cdot 1$ & 9.3 & $5 \cdot 5$ & $10 \cdot 0$ & $<0.001$ & 4.5 & 8.7 \\
\hline Sweetened beverages & 0.7 & 3.0 & $2 \cdot 2$ & $5 \cdot 0$ & $4.5 \S \ddagger$ & $8 \cdot 3$ & $7.5 \S \ddagger \|$ & 11.9 & $<0.001$ & $4 \cdot 2$ & 8.5 \\
\hline Fruits and vegetables juices and drinks & $5 \cdot 1$ & $7 \cdot 6$ & 4.2 & $6 \cdot 7$ & 3.5 & $5 \cdot 8$ & 3.6 & $6 \cdot 3$ & 0.005 & 3.9 & $6 \cdot 4$ \\
\hline Cake-type dessert & 2.9 & 8.4 & 3.6 & 8.9 & 4.0 & 9.4 & 3.5 & 9.6 & 0.663 & 3.6 & $9 \cdot 2$ \\
\hline Sweet biscuits & 4.9 & 7.8 & 3.2 & 5.6 & 3.4 & $6 \cdot 2$ & $2.2 \S$ & 5.6 & $<0.001$ & 3.2 & $6 \cdot 1$ \\
\hline Savoury biscuits & 2.7 & $5 \cdot 3$ & 3.4 & $7 \cdot 1$ & 3.2 & 7.5 & 2.4 & 6.9 & 0.118 & 3.0 & $7 \cdot 0$ \\
\hline Fancy breads & 1.9 & $6 \cdot 1$ & 3.0 & $7 \cdot 7$ & 3.3 & 8.4 & 2.8 & 7.9 & 0.570 & 2.9 & 7.8 \\
\hline Dairy milk & 6.4 & 6.5 & $2.9 \S$ & 3.4 & $2.5 \S$ & $3 \cdot 1$ & $2.0 \S$ & 2.9 & $<0.001$ & 2.9 & 3.9 \\
\hline Pome fruit & $2 \cdot 7$ & 4.4 & 3.5 & $4 \cdot 8$ & $2 \cdot 7$ & 4.2 & $1.3 \S \ddagger \|$ & $2 \cdot 9$ & $<0.001$ & $2 \cdot 6$ & 4.2 \\
\hline Tropical and subtropical fruit & $4 \cdot 2$ & $6 \cdot 7$ & $2.3 \S$ & 4.7 & $1.5 \S$ & 4.1 & $0.8 \S \ddagger$ & $2 \cdot 5$ & $<0.001$ & 1.9 & 4.4 \\
\hline Pastas & 1.2 & 4.5 & 1.5 & $5 \cdot 5$ & $2 \cdot 0$ & 6.5 & 2.4 & $7 \cdot 2$ & 0.001 & 1.9 & $6 \cdot 2$ \\
\hline Pastries & $1 \cdot 1$ & 4.4 & 1.7 & $5 \cdot 1$ & 1.9 & 5.6 & $2 \cdot 3$ & 6.5 & 0.022 & 1.8 & $5 \cdot 6$ \\
\hline Sugar, honey and syrups & 1.7 & 4.5 & 1.7 & 3.9 & 1.6 & 3.8 & 1.9 & $4 \cdot 1$ & 0.187 & 1.7 & 4.0 \\
\hline Poultry-based dishes & $2 \cdot 2$ & $6 \cdot 6$ & 1.4 & 4.0 & 1.7 & 4.9 & 1.5 & 4.7 & 0.817 & 1.6 & 4.8 \\
\hline Chocolates & 1.5 & 4.3 & 1.3 & 3.6 & 1.5 & 4.8 & 1.8 & 5.4 & 0.017 & 1.5 & 4.6 \\
\hline Frozen milk products & 0.8 & $2 \cdot 6$ & 1.5 & 3.6 & $2.0 \S$ & 4.0 & 1.4 & 3.6 & 0.083 & 1.5 & 3.6 \\
\hline Other food groups & 22.8 & 15.6 & 21.9 & 14.0 & 20.2 & $15 \cdot 0$ & $18 \cdot 7$ & $15 \cdot 4$ & $<0.001$ & 20.6 & 14.9 \\
\hline
\end{tabular}

* Data were weighted to account for over- or under-sampling to enable representation of the general Australian children and adolescent population.

$\dagger P_{\text {for trend }}$ across age groups tested by linear regression.

F Indicates $P<0.001$ when compared with participants aged $4-8$ years.

II Indicates $P<0.001$ when compared with participants aged $9-13$ years. 
Table 4. Per consumer percentage dietary glycaemic load contribution from the top twenty food groups, in subjects aged 2-18 years (Mean values and standard deviations)

\begin{tabular}{|c|c|c|c|c|c|c|c|c|c|c|c|}
\hline \multirow[b]{2}{*}{ Food groups } & \multicolumn{2}{|c|}{$2-3$ years } & \multicolumn{2}{|c|}{$4-8$ years } & \multicolumn{2}{|c|}{$9-13$ years } & \multicolumn{2}{|c|}{$14-18$ years } & \multirow[b]{2}{*}{$P_{\text {trend }} \dagger$} & \multicolumn{2}{|c|}{ All children } \\
\hline & Mean & SD & Mean & SD & Mean & SD & Mean & SD & & Mean & SD \\
\hline Bread and bread rolls & $19 \cdot 8$ & 9.8 & $22 \cdot 0$ & 11.7 & 19.6 & $10 \cdot 3$ & $19 \cdot 5$ & $12 \cdot 0$ & 0.023 & 20.4 & $11 \cdot 1$ \\
\hline Cereal-based dishes & $19 \cdot 6$ & 11.5 & $21 \cdot 8$ & $13 \cdot 1$ & $25 \cdot 0$ & $14 \cdot 6$ & $27 \cdot 1$ & $15 \cdot 9$ & $<0.001$ & $24 \cdot 4$ & $14 \cdot 7$ \\
\hline Breakfast cereals (ready to eat) & 14.2 & 8.5 & $15 \cdot 1$ & 8.9 & $15 \cdot 5$ & 7.7 & $19 \cdot 0$ & 11.3 & $<0.001$ & $15 \cdot 9$ & $9 \cdot 2$ \\
\hline Flours, cereals and starches & $25 \cdot 1$ & $16 \cdot 6$ & $26 \cdot 1$ & 14.0 & $26 \cdot 3$ & $17 \cdot 2$ & 30.7 & 16.9 & 0.024 & $27 \cdot 3$ & $16 \cdot 3$ \\
\hline Potatoes & 9.9 & 7.0 & $11 \cdot 1$ & 9.7 & 13.5 & $10 \cdot 8$ & $15 \cdot 2$ & 11.3 & $<0.001$ & 13.0 & 10.5 \\
\hline Sweetened beverages & 9.4 & $7 \cdot 1$ & 10.7 & 5.7 & $12 \cdot 8$ & $9 \cdot 3$ & $16 \cdot 7$ & $12 \cdot 7$ & $<0.001$ & 13.8 & $10 \cdot 4$ \\
\hline Fruits and vegetables juices and drinks & 11.0 & $7 \cdot 8$ & $10 \cdot 0$ & 6.9 & 9.4 & 5.9 & $10 \cdot 9$ & $6 \cdot 3$ & 0.741 & $10 \cdot 1$ & 6.6 \\
\hline Cake-type dessert & $17 \cdot 6$ & $13 \cdot 2$ & $17 \cdot 2$ & 11.9 & $19 \cdot 6$ & 11.5 & $19 \cdot 2$ & $14 \cdot 1$ & 0.229 & 18.5 & $12 \cdot 4$ \\
\hline Sweet biscuits & 11.8 & 8.2 & 8.6 & 6.3 & $9 \cdot 1$ & $7 \cdot 2$ & 9.6 & 8.0 & 0.048 & 9.4 & $7 \cdot 3$ \\
\hline Savoury biscuits & 8.4 & $6 \cdot 3$ & 11.9 & 8.6 & 12.5 & $10 \cdot \overline{2}$ & $14 \cdot 2$ & 10.7 & $<0.001$ & $12 \cdot 0$ & 9.4 \\
\hline Fancy breads & $16 \cdot 2$ & 9.3 & $18 \cdot 3$ & $9 \cdot 3$ & 17.4 & $11 \cdot 2$ & $18 \cdot 0$ & $11 \cdot 1$ & 0.849 & $17 \cdot 7$ & 10.5 \\
\hline Dairy milk & $7 \cdot 7$ & $6 \cdot 4$ & $4 \cdot 1$ & 3.3 & 3.9 & 3.0 & $3.4 \ddagger$ & 3.2 & $<0.001$ & 4.4 & 4.0 \\
\hline Pome fruit & $7 \cdot 2$ & 4.5 & 7.5 & 4.4 & $7 \cdot 0$ & $4 \cdot 1$ & 6.1 & 3.2 & 0.008 & $7 \cdot 1$ & $4 \cdot 2$ \\
\hline Tropical and subtropical fruit & 10.8 & 6.5 & 9.8 & 4.3 & 8.5 & $6 \cdot 2$ & 6.5 & 3.4 & $<0.001$ & 9.1 & 5.5 \\
\hline Pastas & $13 \cdot 6$ & $7 \cdot 8$ & $16 \cdot 2$ & 8.9 & $17 \cdot 1$ & $9 \cdot 7$ & $17 \cdot 4$ & $10 \cdot 6$ & 0.148 & $16 \cdot 7$ & 9.7 \\
\hline Pastries & $12 \cdot 1$ & 8.2 & 13.2 & 7.5 & $12 \cdot 1$ & 8.9 & 13.6 & 9.7 & 0.677 & $12 \cdot 8$ & 8.8 \\
\hline Sugar, honey and syrups & $7 \cdot 7$ & 7.0 & 5.7 & $5 \cdot 2$ & $6 \cdot 1$ & $5 \cdot 3$ & 6.4 & $5 \cdot 1$ & 0.705 & $6 \cdot 2$ & $5 \cdot 4$ \\
\hline Poultry-based dishes & $12 \cdot 6$ & 11.0 & $7 \cdot 7$ & 6.7 & $9 \cdot 0$ & 7.6 & 8.6 & 8.2 & 0.600 & 8.9 & 8.0 \\
\hline Chocolates & 8.2 & $7 \cdot 2$ & $6 \cdot 6$ & 5.6 & 8.0 & 8.4 & 8.5 & 8.9 & 0.100 & $7 \cdot 7$ & $7 \cdot 7$ \\
\hline Frozen milk products & 6.0 & 4.9 & $6 \cdot 8$ & 4.8 & $7 \cdot 0$ & 4.6 & 7.5 & 4.9 & 0.097 & $7 \cdot 0$ & 4.7 \\
\hline Other food groups & $22 \cdot 8$ & $15 \cdot 6$ & $22 \cdot 0$ & 13.9 & $20 \cdot 2$ & $15 \cdot 0$ & $18 \cdot 7$ & $15 \cdot 4$ & $<0.001$ & $20 \cdot 6$ & 14.9 \\
\hline
\end{tabular}

* Data were weighted to account for over- or under-sampling to enable representation of the general Australian children and adolescents population.

$\dagger P_{\text {for trend }}$ across age groups tested by linear regression.

$\ddagger$ Indicates $P<0.001$ when compared with participants aged $2-3$ years. 
carbohydrate intake, as GL is a product of GI and carbohydrate intake. The large sD of total carbohydrate intake supports this. On the other hand, the large sD for the \%GL contribution could be a result of large inter-individual variance in the intake of different food groups. Overall, these results suggest that there is still a substantial portion of the population consuming a high-GI/GL diet, despite a moderate population mean.

It is interesting to note the differences in the results obtained from the per capita and per consumer analyses. Although the per capita analysis provides a good snapshot of the population, the per consumer analysis highlights the great variance in the sources of dietary GL among Australians, as non-consumers were excluded from the respective analysis. For example, the $\%$ GL contribution by cereals and cereal-based products differs by more than $100 \%$ (per capita $10.5 \%$ v. per consumer $24.4 \%$ ), indicating that the per capita results were skewed to the left by consumers with no intake. In practice, healthcare professionals will be able to better tailor their intervention strategies for individuals based on the per consumer results, whereas the per capita results will inform population-based strategies.

Our results revealed that Australian children and adolescents had more than one-third of their dietary GL from cereal-based foods, with breads and bread rolls as the main contributors to dietary GL. This is similar to our previous findings from the 2007 ANCNPAS $^{(20)}$. However, our findings contrast with that from Asian studies ${ }^{(43-45)}$, which indicate that a large proportion (41-64\%) of dietary GI and GL is derived from white rice, the staple food of many eastern countries. A German study also reported different patterns of GL contribution, with bread and bread rolls contributing to more than a quarter of the dietary $\mathrm{GL}^{(46)}$, significantly higher than that observed in the present study. These differences highlights the need to gather countryspecific data on dietary GI and GL to better inform nutrition and public health policy in each nation.

As foods with a GI $<55$ are defined as 'low-GI', a misconception is that a diet that averages 55 represents a low-GI eating pattern ${ }^{(47)}$. However, adult cohort studies suggest that a dietary GI of 45 or below is associated with better health outcomes $^{(47-49)}$. Our results indicate that only $3 \%$ of Australian children and adolescents are actually meeting this cut-off, although whether this lower cut-off applies to children and adolescents remains to be confirmed. Nonetheless, we found that both dietary GI and GL significantly increase with age, driven mainly by increased contribution from low-fibre cereal-based dishes (such as pizzas), potatoes (including French fries) and sweetened beverages. On average, energy-dense nutrient-poor (EDNP) foods contributed almost a quarter of dietary GL.

To address the rising prevalence of childhood overweight/ obesity, evidence is growing that suggests dietary guidelines may need to incorporate recommendations to substitute lower-GI options for higher-GI options within food groups. Recommending wholegrain varieties will increase fibre intake, but it is unlikely to reduce the GI and GL because most have a surprisingly high $\mathrm{GI}^{(22)}$. Reducing the consumption of EDNP foods that are high in refined carbohydrate (maltodextrins, starches and sugars) will contribute to reduced dietary GL. However, specific advice to consume low-GI grain products will also be helpful and concomitantly increase overall micronutrient intake ${ }^{(50,51)}$.
Opponents of the GI/GL concept often cite examples of indulgence foods such as chocolate and ice cream that are low $\mathrm{GI}^{(52-54)}$. However, the GI was never intended as a marker of overall nutritional quality ${ }^{(22)}$. Rather, it should be used as an additional criterion to identify the better options among healthy, core foods, within food groups. Both wholemeal and multigrain breads are commonly considered as healthy choices, but the latter have a lower GI than wholemeal breads. Hence, to effectively and healthily lower dietary GI, Australian children and adolescents should be advised to limit high-GI, EDNP food choices by swapping to healthy low-GI foods such as multigrain breads, most fresh fruits and reduced fat dairy products ${ }^{(22)}$.

A particular strength of our study is the use of a published method to assign GI values to foods ${ }^{(27)}$, which ensured that the best available values were used in the process, thereby increasing the accuracy of the dietary GI and GL analyses. In addition, our findings are generalisable to children and adolescents within the broader Australian population.

The limitations to our study should be noted. First, accurate dietary assessment in children is difficult ${ }^{(55)}$, and some argue that parental reporting is equally unreliable ${ }^{(56,57)}$. In addition, self-reported dietary intake by 24 -h recall relies heavily on the respondent's ability to correctly recall the foods and beverages consumed in the past $24 \mathrm{~h}$, which is subject to memory bias, although measures such as the use of prompt and the multiplepass 24-h recall methodology may have minimised this to a certain extent. These limitations will inevitably result in under- and over-reporting. A study by Rangan et al. ${ }^{(58)}$ suggested that Australian children and adolescents who underreport tend to do so by under-reporting both the frequency and quantity of food intake, and that is true for both core and discretionary items, whereas over-reporters tend to report larger portions of food consumed. They also noted that parents/ guardians tend to report lower intakes of discretionary foods for younger children, resulting in under-reporting. Post hoc analysis (data not shown) revealed a similar picture in our current data set where under-reporters tend to report lower intake of most food groups, whereas over-reporters tend to report higher intake of foods higher in fat such as cakes and biscuits. Unfortunately, because of the lack of PAL data, we were unable to individualise the Goldberg cut-offs according to the specific $\mathrm{PAL}^{(34)}$ of the subjects, although we were able to identify extreme under- and over-reporters. Hence, our results should be interpreted with the potential of some degree of mis-reporting in mind.

Second, we used only the first 24-h recall, which is unlikely to capture the usual dietary pattern of an individual ${ }^{(59)}$. Although the use of statistical methods to estimate usual intakes are available ${ }^{(60-62)}$, the use of one $24-\mathrm{h}$ recall is deemed appropriate by the National Cancer Institute for estimating population means ${ }^{(63)}$. Using only the first $24-\mathrm{h}$ recall collected in a faceto-face interview also reduced the impact of under-reporting associated with telephone interviews ${ }^{(64)}$, which is how the second 24-h recalls were collected. Third, we have grouped foods based on the pre-defined food classification ${ }^{(31)}$, which was not developed with the GI of foods in mind. This meant that foods in the same group could not be adequately differentiated based on their GI. It is more likely to affect processed 
foods such as breakfast cereals than unprocessed foods such as fruit and vegetables, as degree of processing is a key determinant of the GI of food ${ }^{(65)}$

\section{Conclusion}

Australian children and adolescents appear to consume diets with a lower GI than European children, but only approximately $3 \%$ report consuming a low-GI diet, as defined by one with an average $<45$ (the lowest quantile in adult studies). High-GI 'core' foods such as white breads and breakfast cereals were found to account for the majority of the dietary GI and GL, although EDNP foods such as sugarsweetened beverages also contributed significantly. Efforts to lower the dietary GI and GL of Australian children and adolescents by exchanging high-GI foods for low-GI alternatives within core and non-core foods may improve diet quality.

\section{Acknowledgements}

The authors would like to acknowledge The Glycemic Index Foundation for providing the special edition of AUSNUT 2011-2013 database for use in this study.

There are no funders to report for this submission.

A. W. B., J. C. B.-M. and J. C. Y. L. conceived and designed the study. M. J. carried out the study, analysed the data with the help of J. C. Y. L. and wrote the first draft of the manuscript. All authors provided substantial intellectual input into the subsequent edits of the manuscript, and have read and approved the final manuscript. J. C. Y. L. has primary responsibility of the content of this manuscript.

J. C. B.-M. and A. W. B. are co-authors of The New Glucose Revolution and Low GI Diet books (Hachette Livre Australia and Da Capo Press, North America). J. C. B.-M. is the director of a not-for-profit GI-based food endorsement programme in Australia, and manages the University of Sydney GI testing service. A. W. B. is the Chief Scientific Officer and the director of a not-for-profit GI-based food endorsement programme in Australia. J. C. Y. L. received fees from the Glycemic Index Foundation for the sole purpose of coding the AUSNUT 2011-2013 food composition database. M. J. declares she has no conflicts of interest.

\section{Supplementary material}

For supplementary material/s referred to in this article, please visit http://dx.doi.org/10.1017/S0007114516001823

\section{References}

1. Feliciano Pereira P, das Gracas de Almeida C \& Alfenas Rde C (2014) Glycemic index role on visceral obesity, subclinical inflammation and associated chronic diseases. Nutr Hosp 30 , 237-243.

2. Ludwig DS (2002) The glycemic index: physiological mechanisms relating to obesity, diabetes, and cardiovascular disease. JAMA 287, 2414-2423.

3. Scribner KB, Pawlak DB, Aubin CM, et al. (2008) Long-term effects of dietary glycemic index on adiposity, energy metabolism, and physical activity in mice. Am J Physiol Endocrinol Metab 295, E1126-E1131.

4. Barclay AW, Petocz P, McMillan-Price J, et al. (2008) Glycemic index, glycemic load, and chronic disease risk - a meta-analysis of observational studies. Am J Clin Nutr 87, $627-637$.

5. Greenwood DC, Threapleton DE, Evans CE, et al. (2013) Glycemic index, glycemic load, carbohydrates, and type 2 diabetes: systematic review and dose-response meta-analysis of prospective studies. Diabetes Care $\mathbf{3 6}$, 4166-4171.

6. McMillan-Price J \& Brand-Miller J (2006) Low-glycaemic index diets and body weight regulation. Int $J$ Obes 30 , S40-S46.

7. National Health and Medical Research Council (Australia) (2013) Australian Dietary Guidelines. Canberra: NHMRC.

8. Health Canada (2011) Eating Well with Canada's Food Guide - A Resource for Educators and Communicators. Ottawa: Health Canada.

9. Food Standards Agency (2007) FSA nutrient and food based guidelines for UK institutions, Food Standards Agency, London.

10. U.S. Department of Agriculture \& U.S. Department of Health \& Human Services (2015) Scientific report of the 2015 Dietary Guidelines Advisory Committee - advisory report to the Secretary of Health and Human Services and the Secretary of Agriculture. Washington, DC: USDA.

11. Brand-Miller JC, Holt SH, Pawlak DB, et al. (2002) Glycemic index and obesity. Am J Clin Nutr 76, 281S-285S.

12. Ludwig DS (2000) Dietary glycemic index and obesity. J Nutr 130, 280.

13. Hermansen M-LF, Eriksen NMB, Mortensen LS, et al. (2006) Can the glycemic index (GI) be used as a tool in the prevention and management of type 2 diabetes? Rev Diabet Stud 3, 61-71.

14. Louie JC, Brand-Miller JC, Markovic TP, et al. (2010) Glycemic index and pregnancy: a systematic literature review. J Nutr Metab 2010, 282464.

15. Louie JC, Brand-Miller JC \& Moses RG (2013) Carbohydrates, glycemic index, and pregnancy outcomes in gestational diabetes. Curr Diab Rep 13, 6-11.

16. Gnagnarella P, Gandini S, La Vecchia C, et al. (2008) Glycemic index, glycemic load, and cancer risk: a meta-analysis. Am J Clin Nutr 87, 1793-1801.

17. Barba G, Sieri S, Russo MD, et al. (2012) Glycaemic index and body fat distribution in children: the results of the ARCA project. Nutr Metab Cardiovasc Dis 22, 28-34.

18. Murakami K, Miyake Y, Sasaki S, et al. (2011) Dietary glycemic index and glycemic load in relation to risk of overweight in Japanese children and adolescents: the Ryukyus Child Health Study. Int J Obes (Lond) 35, 925-936.

19. Goletzke J, Herder C, Joslowski G, et al. (2013) Habitually higher dietary glycemic index during puberty is prospectively related to increased risk markers of type 2 diabetes in younger adulthood. Diabetes Care 36, 1870-1876.

20. Louie JC, Buyken AE, Heyer K, et al. (2011) Dietary glycaemic index and glycaemic load among Australian children and adolescents. Br J Nutr 106, 1273-1282.

21. Brand-Miller JC, Foster-Powell K \& Atkinson FS (2014) Professor Jennie Brand-Miller's Low GI Diet Shopper's Guide 2015. Sydney: Hachette Australia.

22. Atkinson FS, Foster-Powell K \& Brand-Miller JC (2008) International tables of glycemic index and glycemic load values: 2008. Diabetes Care 31, 2281-2283.

23. Australian Bureau of Statistics (2012) Australian Health Survey 2011-2012. http://www.abs.gov.au/ausstats/abs@.nsf/Lookup/ 4364.0.55.001main+features12011-12 (accessed May 2015). 
24. Australian Bureau of Statistics (2013) Australian Health Survey: Users' Guide, 2011-13. http://www.abs.gov.au/ausstats/ abs@.nsf/Lookup/74D87E30B3539C53CA257BBB0014BB36? opendocument (accessed June 2015).

25. Cole TJ \& Lobstein T (2012) Extended international (IOTF) body mass index cut-offs for thinness, overweight and obesity. Pediatr Obes 7, 284-294.

26. Food Standards Australia New Zealand (2014) AUSNUT 20112013 - food composition database. http://www.food standards.gov.au/science/monitoringnutrients/ausnut/pages/ default.aspx (accessed May 2015).

27. Louie JCY, Flood VM, Atkinson FS, et al. (2015) Methodology for assigning appropriate glycaemic index values to an Australian food composition database. J Food Compos Anal 38, 1-6.

28. Louie JCY, Barclay AW \& Brand-Miller JC (2015) Assigning glycaemic index values to foods in a recent Australian food composition database. Eur J Clin Nutr 70, 280-281.

29. Chen YJ, Sun FH, Wong SH, et al. (2010) Glycemic index and glycemic load of selected Chinese traditional foods. World $J$ Gastroenterol 16, 1512-1517.

30. Sydney University Glycemic Index Research Service (2012) GlycemicIndex.com. http://www.glycemicindex.com (accessed April-June 2012).

31. Food Standards Australia New Zealand (2015) AUSNUT 2011-13 food and dietary supplement classification system. http://www.foodstandards.gov.au/science/monitoringnutrients/ ausnut/ausnutdatafiles/Pages/foodclassification.aspx (accessed June 2015).

32. Wolever TM, Jenkins DJ, Jenkins AL, et al. (1991) The glycemic index: methodology and clinical implications. $A m \mathrm{~J}$ Clin Nutr 54, 846-854.

33. Poslusna K, Ruprich J, de Vries JHM, et al. (2009) Misreporting of energy and micronutrient intake estimated by food records and 24 hour recalls, control and adjustment methods in practice. Br J Nutr 101, S73-S85.

34. Goldberg GR, Black AE, Jebb SA, et al. (1991) Critical evaluation of energy intake data using fundamental principles of energy physiology: 1 . Derivation of cut-off limits to identify under-recording. Eur J Clin Nutr 45, 569-581.

35. Data Analysis Australia (2012) Sampling and weighting - a better practice guide for practitioners. http://www.daa.com. $\mathrm{au} /$ analytical-ideas/sampling-and-weighting/ (accessed June 2015).

36. Streiner DL (2015) Best (but oft-forgotten) practices: the multiple problems of multiplicity - whether and how to correct for many statistical tests. Am J Clin Nutr 102, 721-728.

37. O'Sullivan TA, Lyons-Wall P, Bremner AP, et al. (2010) Dietary glycaemic carbohydrate in relation to the metabolic syndrome in adolescents: comparison of different metabolic syndrome definitions. Diabetic Med 27, 770-778.

38. Murakami K, McCaffrey TA, Gallagher AM, et al. (2014) Dietary glycemic index and glycemic load in relation to changes in body composition measures during adolescence: Northern Ireland Young Hearts Study. Int J Obes (Lond) 38, 252-258.

39. Joslowski G, Goletzke J, Cheng G, et al. (2012) Prospective associations of dietary insulin demand, glycemic index, and glycemic load during puberty with body composition in young adulthood. Int J Obes (Lond) 36, 1463-1471.

40. Joslowski G, Halim J, Goletzke J, et al. (2015) Dietary glycemic load, insulin load, and weight loss in obese, insulin resistant adolescents: RESIST study. Clin Nutr 34, 89-94.

41. Gopinath B, Flood VM, Rochtchina E, et al. (2012) Influence of high glycemic index and glycemic load diets on blood pressure during adolescence. Hypertension 59, 1272-1277.
42. Murakami K, McCaffrey TA \& Livingstone MB (2013) Dietary glycaemic index and glycaemic load in relation to food and nutrient intake and indices of body fatness in British children and adolescents. Br J Nutr 110, 1512-1523.

43. Murakami K, Sasaki S, Takahashi Y, et al. (2008) Reproducibility and relative validity of dietary glycaemic index and load assessed with a self-administered diet-history questionnaire in Japanese adults. Br J Nutr 99, 639-648.

44. Murakami K, Sasaki S, Takahashi Y, et al. (2006) Dietary glycemic index and load in relation to metabolic risk factors in Japanese female farmers with traditional dietary habits. Am J Clin Nutr 83, 1161-1169.

45. Hui LL \& Nelson EAS (2006) Meal glycaemic load of normalweight and overweight Hong Kong children. Eur J Clin Nutr 60, 220-227.

46. Buyken AE, Dettmann W, Kersting M, et al. (2005) Glycaemic index and glycaemic load in the diet of healthy schoolchildren: trends from 1990 to 2002, contribution of different carbohydrate sources and relationships to dietary quality. Br J Nutr 94, 796-803.

47. Brand-Miller JC (2009) Glycaemic index and glycaemic load: crunch time? Nutr Diet 66, 136-137.

48. Salmeron J, Ascherio A \& Rimm E (1997) Dietary fiber, glycaemic load, and risk of NIDDM in men. Diabetes Care 20, 545-550

49. Salmeron J, Manson J, Stampfer M, et al. (1997) Dietary fiber, glycaemic load, and risk of non-insulin dependent diabetes mellitus in women. JAMA 277, 472-477.

50. Goletzke J, Buyken AE, Louie JC, et al. (2015) Dietary micronutrient intake during pregnancy is a function of carbohydrate quality. Am J Clin Nutr 102, 626-632.

51. Louie JCY, Buyken AE, Brand-Miller JC, et al. (2012) The link between dietary glycemic index and nutrient adequacy. $A m \mathrm{~J}$ Clin Nutr 95, 694-702.

52. Franz MJ (2003) The glycemic index: not the most effective nutrition therapy intervention. Diabetes Care 26, 2466-2468.

53. Pi-Sunyer FX (2002) Glycemic index and disease. Am J Clin Nutr 76, 290S-298S.

54. Pi-Sunyer X (2005) Do glycemic index, glycemic load, and fiber play a role in insulin sensitivity, disposition index, and type 2 diabetes? Diabetes Care 28, 2978-2979.

55. Livingstone MB \& Robson PJ (2000) Measurement of dietary intake in children. Proc Nutr Soc 59, 279-293.

56. Klesges RC, Klesges LM, Brown G, et al. (1987) Validation of the 24-hour dietary recall in preschool children. J Am Diet Assoc 87, 1383-1385.

57. Basch CE, Shea S, Arliss R, et al. (1990) Validation of mothers' reports of dietary intake by four to seven year-old children. Am J Public Health 80, 1314-1317.

58. Rangan A, Allman-Farinelli M, Donohoe E, et al. (2014) Misreporting of energy intake in the 2007 Australian children's survey: differences in the reporting of food types between plausible, under- and over-reporters of energy intake. J Hum Nutr Diet 27, 450-458.

59. Biro G, Hulshof K, Ovesen L, et al. (2002) Selection of methodology to assess food intake. Eur J Clin Nutr 56, S25-S32.

60. Tooze JA, Kipnis V, Buckman DW, et al. (2010) A mixedeffects model approach for estimating the distribution of usual intake of nutrients: the NCI method. Stat Med 29, 2857-2868.

61. Harttig U, Haubrock J, Knuppel S, et al. (2011) The MSM program: web-based statistics package for estimating usual dietary intake using the multiple source method. Eur J Clin Nutr 65, Suppl. 1, S87-S91.

62. Dekkers AL, Verkaik-Kloosterman J, van Rossum CT, et al. (2014) SPADE, a new statistical program to estimate habitual 
dietary intake from multiple food sources and dietary supplements. J Nutr 144, 2083-2091.

63. National Cancer Institute (2015) Dietary assessment primer. Summary tables: recommendations on potential approaches to dietary assessment for different research objectives requiring group-level estimates. http://dietassessmentprimer. cancer.gov/approach/table.html (accessed May 2015).
64. Yanek LR, Moy TF, RaqueÑO JV, et al. (2000) Comparison of the effectiveness of a telephone 24-hour dietary recall method vs an in-person method among urban AfricanAmerican women. I Am Diet Assoc 100, 1172-1177.

65. Trout DL, Behall KM \& Osilesi O (1993) Prediction of glycemic index for starchy foods. Am J Clin Nutr $\mathbf{5 8}$, 873-878. 